\title{
Comparison of temperatures simulated by GCMs, RCMs and statistical downscaling: potential application in studies of future crop development
}

\author{
M. Moriondo*, M. Bindi \\ Department of Agronomy and Land Management, University of Florence, Piazzale delle Cascine 18, 50144 Florence, Italy
}

\begin{abstract}
We evaluated the performance of a general circulation model (HadCM3), a regional circulation model (HadRM3P) and an artificial neural network (ANN), in reproducing daily maximum and minimum temperature $\left(T_{\max }\right.$ and $T_{\min }$ ) at site scale (Florence, Italy) for the present climate. The $T_{\max }$ and $T_{\min }$ values that were observed and those reproduced by HadCM3, HadRM3P and ANN for both the present and future climate scenarios (IPCC scenarios A2 and B2) were then used as input data in a cropping systems simulation model (CropSyst). In particular, climatic impact on the phenological developmental stages of a summer crop (sunflower Helianthus annuus L.) and winter crop (durum wheat Triticum aestivum L.) were evaluated. In addition, the frequency of extreme climatic events during specific crop phenological stages (i.e. number of events with $T_{\max }$ and $T_{\min }$ above and below stressful thresholds) were evaluated. The comparison between observed $T_{\max }$ and $T_{\min }$ values and those produced by HadCM3, HadRM3P and ANN for the present climate, provided evidence for a higher accuracy of the ANN model in simulating these variables. The crop phenological stages and the related extreme climate events were therefore also better reproduced using the ANN climate data. The use of HadCM3 and HadRM3P climate data in climate change impact assessments seemed to result in an overestimation of the impacts (i.e. greater reduction in the length of development phases and greater changes in the frequency of extreme climate events during the most sensitive development stages) compared with those obtained using ANN climate data.
\end{abstract}

KEY WORDS: Crop development - Crop simulation model $\cdot$ Extreme climate events $\cdot$ Sunflower · Winter wheat Resale or republication not permitted without written consent of the publisher

\section{INTRODUCTION}

Outputs of General Circulation Models (GCMs) have been widely used to estimate possible effects of global climate change on agriculture by using climate scenarios generated as inputs in crop growth simulation models (Haskett et al. 2000, Osborne et al. 2000, Izaurralde et al. 2003, Rosenberg et al. 2003). However, in general their simulations of climate change are computed for wide grids (e.g. 2 to $3^{\circ}$ resolution). As a result, GCMs are not directly suitable for local impact studies, since local climate also depends on topographical features, such as elevation or aspect, that are not included in GCMs with such resolution.
To fill this gap, several downscaling techniques have been developed which can be clustered into 2 conceptually distinct approaches: nested modelling (such as the Regional Circulation Model, RCM) and empirical downscaling that uses GCM large-scale predictions to develop regional climate change scenarios (Sánchez et al. 2004).

In the first approach, the outputs of GCMs grid cells are used to provide boundary conditions for other models with higher resolution $(50 \times 50 \mathrm{~km}$, approx.), which better represent local topography and provide a more realistic simulation of fine-scale weather features. Recent studies have shown the capacity of RCMs to reproduce fine-scale features of different regional 
climates (Hulme et al. 2002). These, however, still exhibit systematic errors due to imperfect representation of even smaller-scale features.

Empirical downscaling approaches are generally based on the assumption that GCMs are reliable predictors of both large-scale variables and atmospheric conditions which are sufficiently far removed from the surface of the earth. This approach does not require lengthy computation times and is based on finding clear relationships between large-scale atmospheric variables and local climate. Among these atmospheric variables, many recent studies have used large-scale circulation variables (e.g. geopotential height or sea level pressure) as the only driving parameters in specifying a range of surface variables including temperature (Chen \& Chen 2003), precipitation (Bárdossy 1997) and wind speed (Sailor et al. 2000). However, the assumption that surface variables can be derived only from large-scale circulation variables may not be realistic, because atmospheric circulation may not be the only dominant agent in determining surface climate variables. In order to avoid potential problems due to this uncertainty, many authors included among the predictors additional variables such as free atmospheric temperature or, equivalently thickness and moisture (e.g. Widmann \& Schär 1997, Huth 2001, 2002).

Recently, non-linear approaches have been developed (in particular, the artificial neural network, ANN) and adopted as tools to downscale local and regional climate variables from large-scale atmospheric circulation variables (Crane \& Hewitson 1998, Wilby et al. 1998, 1999, Trigo \& Palutikof 1999, Cavazos 2000, Sailor et al. 2000, Olsson et al. 2001). This approach increased downscaling accuracy when compared to a linear model (McGinnis 1994, Weichert \& Bürger 1998, Trigo \& Palutikof 1999). A regression analysis is constrained by the need to adopt a linear relationship between input and output variables, whilst the ANN model can be trained to find the best relationship between atmospheric and surface variables without predefined constraints (Trigo \& Palutikof 1999). In particular, the multi-layer perceptron (MLP) neural network has been applied to a wide variety of climatological problems (Gardner \& Dorling 1998, Trigo \& Palutikof 1999, Cannon \& Whitfield 2002) due to the extreme flexibility of the model (Hornik et al. 1989).

The effect of spatial scaling of climate variables for input in crop simulation models has been investigated in many studies (Mearns et al. 1996, 2001, 2003, Easterling et al. 2001, Adams et al. 2003, Carbone et al. 2003, Doherty et al. 2003, Tsvetsinskaya et al. 2003). In particular, these studies focussed on analysing the impact on mean crop yields, without considering the role of spatial scale in detecting extreme events affecting yield variability. During key developmental stages of a crop, extreme climatic events may have a dramatic impact on final production, even if weather conditions are generally favourable for the rest of the growing season.

Therefore, this work aimed to determine the performance of a GCM (HadCM3), an RCM (HadRM3P) and an ANN in reproducing daily maximum and minimum temperature $\left(T_{\max }\right.$ and $\left.T_{\min }\right)$ at site scale (Florence, Italy). Additionally, the work aimed to evaluate the differences induced by these simulated temperatures on the appearance of the main phenological stages of a summer (i.e. sunflower) and a winter crop (i.e. durum wheat), and in terms of frequency of extreme climatic events during phenological stages of these crops (i.e. number of events with $T_{\max }$ and $T_{\min }$ above and below stressful thresholds).

\section{MATERIALS AND METHODS}

\subsection{Climatic datasets}

\subsubsection{Observed climate data}

$T_{\max }$ and $T_{\min }$ recorded in Florence at the Ximeniano weather station $\left(11.25^{\circ} \mathrm{E}, 43.75^{\circ} \mathrm{N}, 80 \mathrm{~m}\right.$ a.s.l.) for the period 1951-1990 were used as 'observed data' for comparison with simulated data. In particular, data collected from 1951 to 1976 were used to find and test the relationships with large-scale atmospheric variables (i.e. ANN), while data from 1977 to 1990, i.e. the 'present period', were used to analyse the performances of GCM, RCM and ANN in reproducing the daily temperature pattern. The quality (i.e. homogeneity) of the entire data set was checked in a previous study (Kumar et al. 2005).

\subsubsection{NCEP-NCAR reanalysis data}

Observed large-scale atmospheric variables for the period 1951-1990 were obtained from the reanalysis of NCEP-NCAR (National Centers for Environmental Prediction-National Center for Atmospheric Research) data. Daily mean of geo-potential height at 500 and $850 \mathrm{hPa}$ (HGT500, HGT850), relative humidity $(\mathrm{RH})$, mean sea level pressure (MSLP) with a grid resolution of $2.5^{\circ} \times 2.5^{\circ}$ were interpolated to match GCM spatial resolution $\left(2.5^{\circ}\right.$ Lat. $\times 3.75^{\circ}$ Long. $)$. The resulting time series of the grid cell nearest to Florence ${ }^{1}$

\footnotetext{
1The most appropriate NCEP-NCAR, GCM and RCM grid boxes were selected by carrying out a preliminary analysis on the differences between observed and simulated data of $T_{\max }$ and $T_{\min }$ (data not shown)
} 


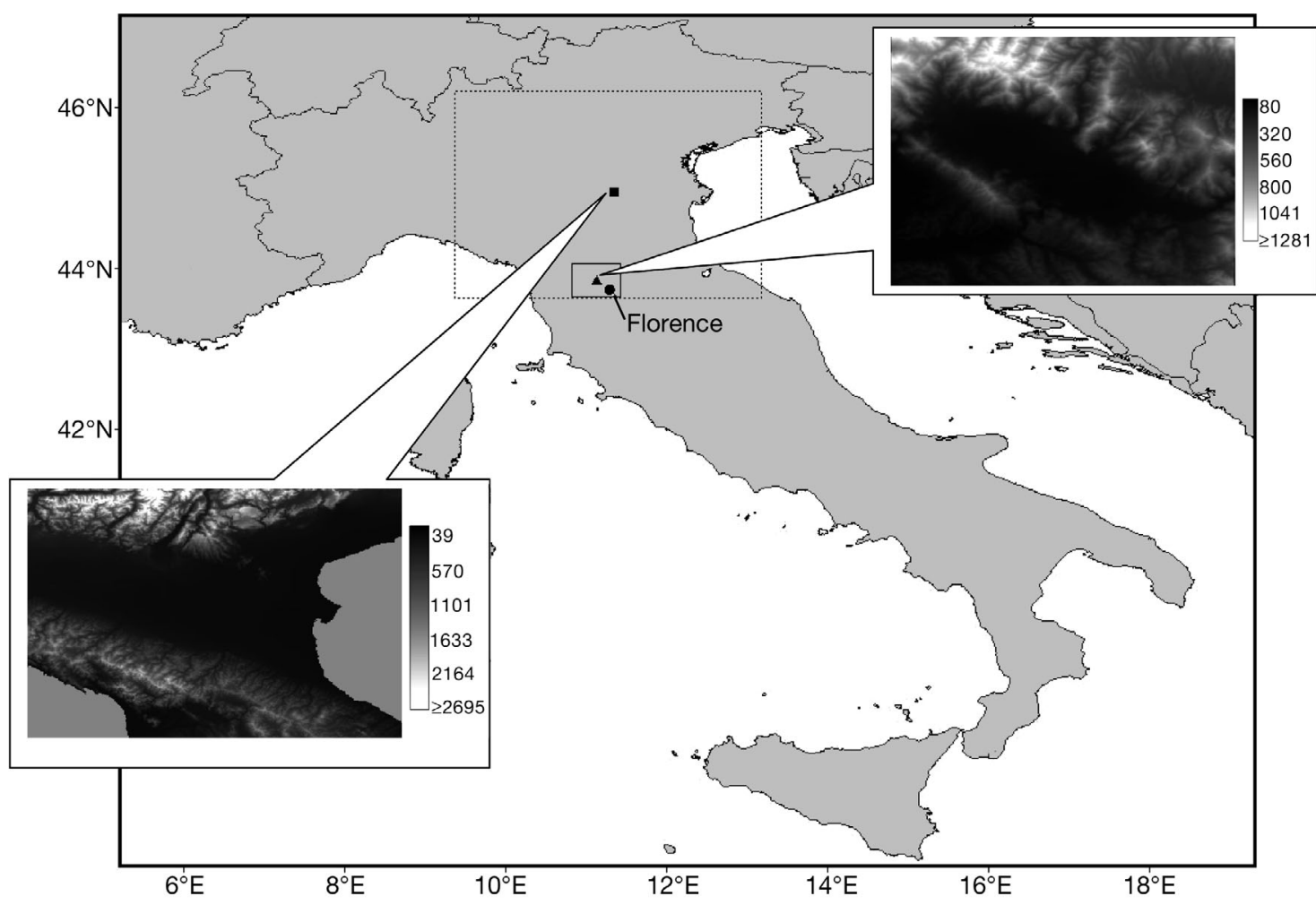

Fig. 1. Location of grid-cells used in this analysis. Dashed line: HadCM3 and NCEP-NCAR grid cells, solid line: HadRM3P grid cell, fill circle: location of Ximeniano weather station, Florence. Morphology of the HadCM3 and HadRM3P grid cells is shown (elevation in $\mathrm{m}$ )

(Fig. 1) were used as predictor variables to develop and test the ANN model with observed $T_{\max }$ and $T_{\min }$ data (1951-1976), and to validate the capability of GCMs to reproduce large-scale variables and atmospheric conditions (1977-1990).

\subsubsection{GCM and RCM data}

The GCM and RCM adopted in this work were the HadCM3 and HadRM3P, respectively, developed by the Hadley Centre, UK. HadCM3 is a coupled atmosphere-ocean GCM described by Gordon et al. (2000) and Pope et al. (2000). The atmospheric component of HadCM3 has 19 levels with a horizontal resolution of $2.5^{\circ}$ Lat. $\times 3.75^{\circ}$ Long., while the oceanic component has 20 levels with a horizontal resolution of $1.25^{\circ}$ Lat. $\times$ $1.25^{\circ}$ Long. The model run was forced between 1860 and 1990, and included observed changes in greenhouse gases and aerosols. From 1990 onwards, a number of scenarios of future changes in greenhouse gases and aerosols were used to drive the model run.

HadRM3P has a spatial resolution of $0.44^{\circ}$ Lat. $\times$ $0.44^{\circ}$ Long. and is the result of a dynamical downscaling. It takes boundary conditions from a coarser resolution global model and provides a higher spatial resolu- tion of local topography and more realistic simulations of fine-scale weather features. In particular, the outputs from HadCM3 experiments provide the boundary conditions to drive a high resolution $(\sim 120 \mathrm{~km})$ model of the global atmosphere (HadAM3P). In turn, the outputs from this model provide the boundary conditions to drive the HadRM3P. This double nesting approach is performed to improve the accuracy of the simulated climate.

In order to simulate climate change, 2 emission scenarios (A2 and B2) were selected among those proposed by the Special Report on Emission Scenarios (SRES) (IPCC 2000) for their wide and representative range of changes in temperature patterns.

$T_{\max }$ and $T_{\min }$ simulated from HadCM3 and HadRM3P for the periods 1977-1990 and 2087-2100 were extracted for the respective grid cells closest to Florence (Fig. 1). In particular, as mentioned above, the HadCM3 data for the present climate were compared with the NCEP-NCAR data to test the capability of the GCM to reproduce large-scale variables and atmospheric conditions. HadCM3, HadRM3P and ANN data reproducing both present and future climate conditions were used as input for a crop growth simulation model (CropSyst model) to identify the role of temperature data in climate change impact studies. 


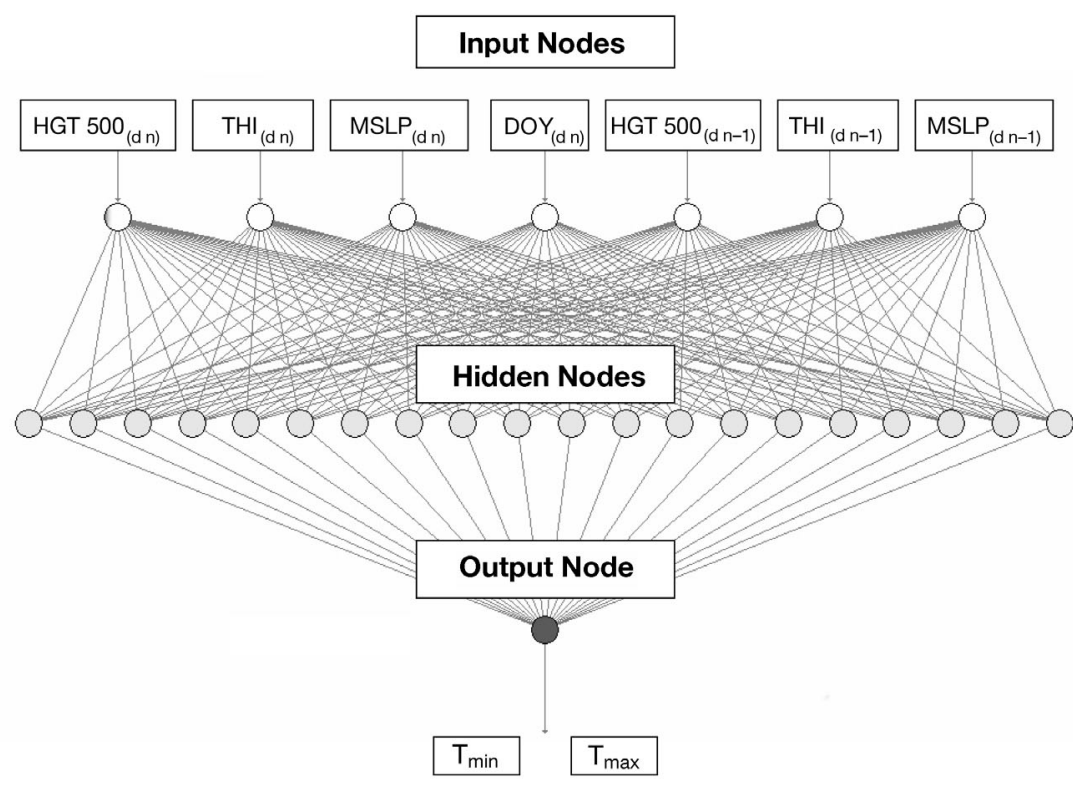

Fig. 2. Structure of the artificial neural network. HGT 500: geo-potential height at $500 \mathrm{hPa}$, THI: thickness $850-500 \mathrm{hPa}$ geo-potential height, MSLP: mean sea level pressure, DOY: day of year

\subsection{ANN model}

The ANN approach can be viewed as a computer system that is made up of several simple and highly interconnected processing elements similar to the neuron architecture of the human brain (McClelland et al. 1986). Problems which are not easily solvable using a normal statistical approach can be solved a by neural network. In particular, ANN can be used to solve problems where the inputs and the corresponding outputs are known, but the relationships between those elements are not well understood (Bindi \& Maselli 2001).

\subsubsection{ANN structure and inputs}

The ANN structure adopted is an MLP with a feedforward configuration. This structure, has been demonstrated to solve climatic problems (Gardner \& Dorling 1998, Trigo \& Palutikof 1999). The MLP consists of a system of simple interconnected nodes or neurons assembled in several different layers. Each node calculates a linear combination of weighted inputs from the links feeding into it. The summed value is transformed using linear or non linear functions. The output obtained is then passed as an input to other nodes of the next layer. These calculations are repeated until the output layer is reached.

More specifically, an ANN-MLP structure with 3 layers and 20 nodes per layer was selected (Fig. 2). A nonlinear transfer function (log-sigmoid) was selected for all nodes and layers and a back-propagation algorithm (Rumelhart et al. 1986) was used for training the ANN. The optimal number of hidden nodes (over a range of 5 to 25 with a 5 node step) and the proper learning rate and momentum were determined through sensitivity analyses.

Large-scale circulation indexes for both the current day and the previous day were used as ANN input nodes, and observed $T_{\max }$ and $T_{\min }$ as ANN output nodes. Accordingly, HGT 500, MSLP and 850-500 hPa thickness (THI) collected from the NCEP-NCAR grid point nearest to Florence were used as input nodes of the ANN model. Moreover, since air temperature in Florence has a strong annual cycle, the day of the year (DOY) was also considered as an additional input node using the expression modified from Régnière \& Bolstad (1994) to account for the circularity of the calendar dates:

$$
\mathrm{DOY}=\frac{1}{2}\left[1-\cos \left(2 \pi \frac{\mathrm{Day}-31}{365}\right)\right]
$$

Other climate parameters, such as cloudiness, solar radiation and relative air humidity were also analysed as possible ANN input nodes. Cloudiness and solar radiation, however, were discarded because they were poorly correlated with predictands $\left(T_{\max }\right.$ and $\left.T_{\min }\right)$. Relative humidity was excluded from the ANN inputs because it was not well reproduced by GCM, and thus not feasible for climate change assessments (Fig. 3).

Since the basic assumptions of the ANN model were not verifiable under future climate scenarios, it was assumed that the statistical relationships developed for the present climate were also valid for future climate scenarios (A2 and B2) (Trigo \& Palutikof 1999).

\subsubsection{ANN testing and validation}

The observed and the NCEP-NCAR data for the period 1951-1976 were used as outputs and inputs of the ANN model, respectively. The ANN model testing was carried out using 3 procedures: (1) Simple testing during the training period (ST), in which a random sub-set of days ( $20 \%$ of total data set) was chosen for testing the ANN; (2) Simple testing using a fixed period (1972-1976) of the training dataset (SP); (3) Cross validation $(\mathrm{CV})$, in which each year, in turn, is omitted and used to test the ANN (Michaelsen 1987). 

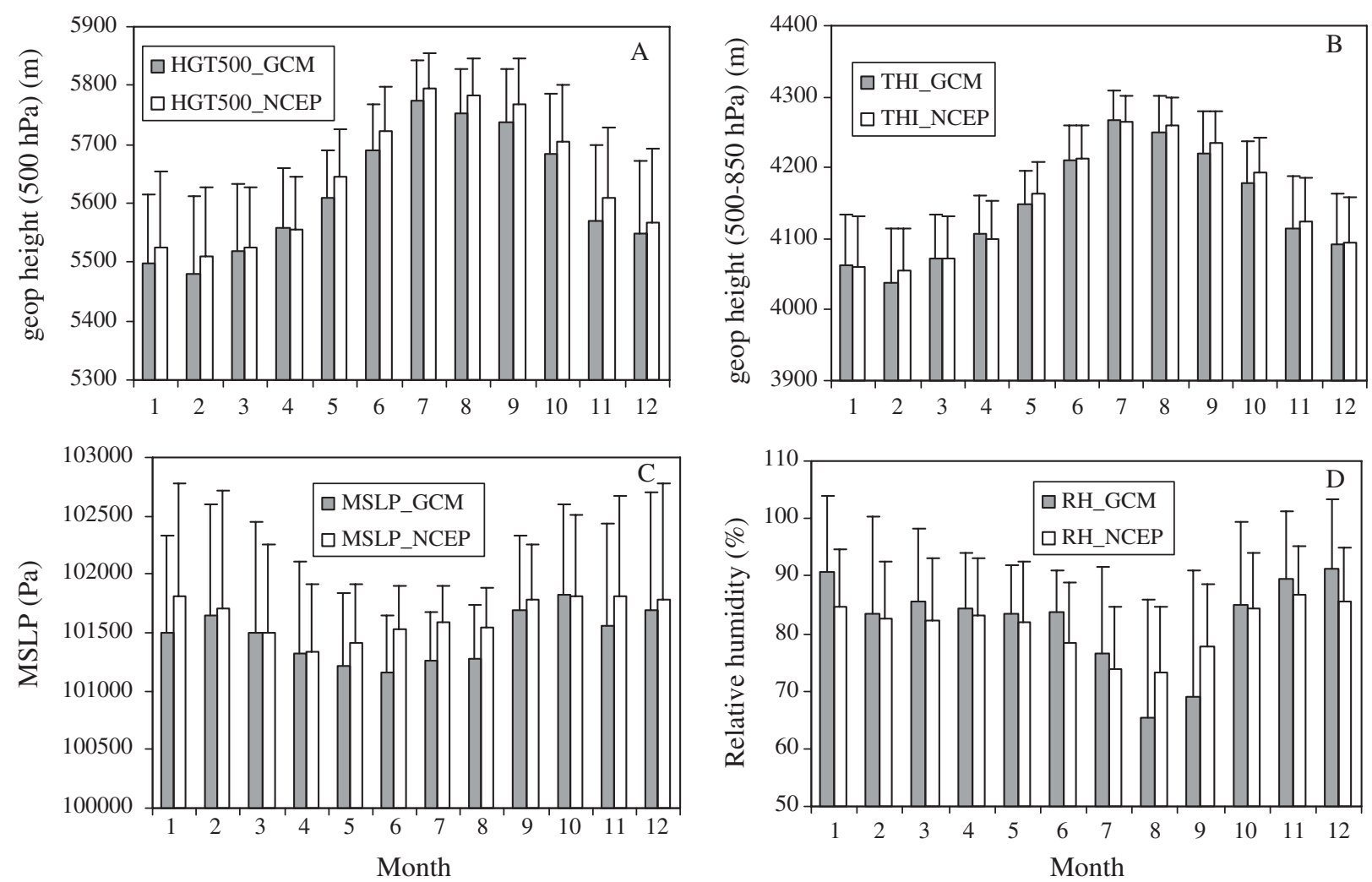

Fig. 3. NCEP-NCAR and GCM monthly means (from 1977 to 1990). (A) geo-potential height at 500 hPa (HGT500), (B) difference of geo-potential height at 500 and $850 \mathrm{hPa}$ (THI), (C) mean sea level pressure (MSLP), (D) relative humidity (RH)

Since the ANN model was applied for the climate impact analyses on crop development by adopting the GCM data as predictors, a validation of the performance of ANN model in reproducing $T_{\max }$ and $T_{\min }$ daily data was performed using the GCM data as predictors for the remaining period (1977-1990).

\subsection{Cropping systems simulation model}

The cropping systems simulation model (CropSyst) is a multi-year, multi-crop, daily time-step crop growth simulation model (Stockle et al. 2003). The model simulates the soil water budget, soil-plant nitrogen budget, crop canopy and root growth, crop phenology, dry matter production, yield, residue production and decomposition, and erosion. In this study, the model was used to simulate crop development. More specifically, in CropSyst the simulation of crop development is mainly based on the thermal time required to attain specific development stages. Thermal time is calculated as growing degree days $\left(\mathrm{GDD},{ }^{\circ} \mathrm{C} \mathrm{d}^{-1}\right)$ accumulated throughout the growing season (from planting until harvest). Average air temperature above a base temperature and below a cutoff temperature is considered for GDD calculation. Moreover, the simulation of crop development considers other environmental aspects such as day length, low temperature requirements, i.e. 'vernalisation' ${ }^{2}$, and soil water content.

Observed and simulated $T_{\max }$ and $T_{\min }$ of the 4 datasets (weather station, GCM, RCM and ANN data) were used as input variables of CropSyst to simulate the dates (day of the year, DOY) of the main developmental stages (sowing, emergence, anthesis, grain filling, physiological maturation) in winter wheat and sunflower.

A previous calibration of CropSyst crop developmental parameters was performed using observed $T_{\max }$ and $T_{\min }$ and development dates of wheat and sunflower collected for the study area by Narciso et al. (1992) (Table 1).

Wheat is an autumn-sown crop that requires cold temperature in the early development stages to meet the requirements of vernalization. In the Mediterranean basin, there is only a short period over which vernalization can take place and thus wheat is sown close to this period (Harrison \& Butterfield 1996). In our

\footnotetext{
$\underline{2}$ Vernalisation is a process required for certain plant species to enter the reproductive stage through exposure to low, nonfreezing temperatures. Thermal time accumulation is limited until vernalization requirements are met
} 
Table 1. Triticum aestivum and Helianthus annuus. List of the parameters set for simulating wheat and sunflower development. GDD: growing degree days accumulated from the sowing date to each development stage; ns: parameters not set to simulate sunflower development; 5 dd: 5 consecutive days

\begin{tabular}{|lcc|}
\hline Parameters & Wheat & Sunflower \\
\hline Starting simulation (DOY) & 305 & 74 \\
Conditions for sowing time & $<7$ & $>13$ \\
$\quad\left(T\right.$ mean for 5 dd) $\left({ }^{\circ} \mathrm{C}\right)$ & & \\
Base temperature $\left({ }^{\circ} \mathrm{C}\right)$ & 10 & 10 \\
Cutoff temperature $\left({ }^{\circ} \mathrm{C}\right)$ & 25 & 35 \\
Sowing temperature $\left({ }^{\circ} \mathrm{C}\right)$ & 7 & 13 \\
Emergence $(\mathrm{GDD})$ & 140 & 70 \\
Anthesis (GDD) & 370 & 500 \\
Grain filling $(\mathrm{GDD})$ & 500 & 532 \\
Maturity $(\mathrm{GDD})$ & 800 & 1300 \\
Low temperature for optimal & 3 & $\mathrm{~ns}$ \\
vernalisation $\left({ }^{\circ} \mathrm{C}\right)$ & & \\
High temperature for optimal & 10 & $\mathrm{~ns}$ \\
vernalisation $\left({ }^{\circ} \mathrm{C}\right)$ & & \\
Days needed to complete vernalisation & 50 & $\mathrm{~ns}$ \\
\hline
\end{tabular}

simulations, the sowing dates were matched when, starting from November 1, mean temperature for 5 consecutive days was $7^{\circ} \mathrm{C}$ or lower. Sunflower is a spring-sown crop requiring high radiation for a good yield level, thus sowing dates are established to intercept the maximum radiation during the growing season. In our simulations, this time was matched when, starting from March 15, mean temperature for 5 consecutive days was $13^{\circ} \mathrm{C}$ or higher.

The frequency of extreme climatic events during the sensitive development stages of a crop was monitored for present and future scenarios. For each stage, extreme events were defined as those days where daily $T_{\max }$ and $T_{\min }$ exceeded a temperature threshold in an interval of $\pm 3 \mathrm{~d}$ around the dates coinciding with important development stages (Table 2). In other words, for each developmental stage the number of events when $T_{\min }$ was below the minimum threshold (hereafter given as $\mathrm{EE}<T_{\min }$ ) and when $T_{\max }$ was above the maximum threshold (hereafter given as EE $>T_{\max }$ ) were calculated. $T_{\max }$ and $T_{\min }$ thresholds for each phase were defined as those temperatures below and above which the crop experienced unacceptable growing conditions (Narciso el al. 1992, Porter \& Gawith 1999).

\subsection{Statistical analyses}

The evaluation of the accuracy of the ANN model in simulating $T_{\max }$ and $T_{\min }$ during the testing phase was performed by calculating: (1) root mean square error
Table 2. Triticum aestivum and Helianthus annuus. Thresholds defining extreme events for winter wheat and sunflower according to their development stages

\begin{tabular}{|lcccc|}
\hline \multirow{2}{*}{ Phase } & \multicolumn{2}{c}{ Wheat } & \multicolumn{2}{c|}{ Sunflower } \\
& $T_{\min }$ & $T_{\max }$ & $T_{\min }$ & $T_{\max }$ \\
\hline Sowing & 0 & - & 5 & - \\
Emergence & 0 & - & 5 & - \\
Anthesis & 10 & 32 & 15 & 37 \\
Grain filling & - & 32 & - & 37 \\
\hline
\end{tabular}

Table 3. Statistical analysis of the performances of ANN in reproducing temperature data. $\mathrm{R}^{2}$ : coefficient of determination; MAE: mean absolute error; RMSE: root mean square error; ST: simple validation during training; SP: simple valida-

tion using a period of the dataset; CV: cross validation

\begin{tabular}{|lrlllll|}
\hline & & \multirow{2}{*}{$T_{\max }$} & & & $T_{\min }$ \\
& $\mathrm{R}^{2}$ & MAE & RMSE & $\mathrm{R}^{2}$ & MAE & RMSE \\
\hline $\mathrm{ST}$ & 0.93 & 1.67 & 2.1 & 0.87 & 1.78 & 2.2 \\
$\mathrm{SP}$ & 0.93 & 1.55 & 1.98 & 0.89 & 1.68 & 2.0 \\
$\mathrm{CV}$ & 0.91 & 1.59 & 2.0 & 0.89 & 1.72 & 2.1 \\
& & & & & & \\
\hline
\end{tabular}

(RMSE); (2) mean absolute error (MAE) and (3) coefficient of determination $\left(\mathrm{R}^{2}\right)$. The ability to reproduce climate ( $T_{\max }$ and $T_{\min }$ ) and crop (development phase) parameters through GCM, RCM and ANN models was determined as follows: (1) performing ANOVA statistical analyses and (2) reproducing the distribution of the observed and simulated temperatures by means of a comparison of the percentiles of the cumulated empirical distribution function (quantile-quantile [qq] plots).

\section{RESULTS AND DISCUSSION}

\subsection{Climate data analyses}

\subsubsection{ANN performance}

The testing analysis showed a high level of correspondence between observed and simulated data (Table 3), indicating the robustness of our procedure in generating temperature data. In particular, the determination coefficients were always $>0.91$ whereas the MAE and RMSE were $<1.7$ and $<2.1^{\circ} \mathrm{C}$, respectively. Moreover, the analysis of the relative importance of each ANN input showed that large-scale circulation indexes such as HGT550 and MSLP had the highest relevance in determining the ANN outputs with a relative importance of 45 and $25 \%$, respectively. In contrast, the other 2 selected predictors (THI and DOY) had lower relative importance (20 and 10\%). 


\subsubsection{Comparison between observed and simulated data}

Present climate. The results indicate that both HadCM3 (GCM) and HadRM3P (RCM) were not able to correctly reproduce the $T_{\max }$ and $T_{\min }$ patterns of the Florence weather station for most of the year (Fig. 4). In particular, the seasonal means of $T_{\max }$ and $T_{\min }$ simulated by GCM were largely lower than those observed for all 4 seasons (Table 4). The differences were always statistically significant $(\mathrm{p}<0.05)$ and ranged from -5.7 to $-7.3^{\circ} \mathrm{C}$ for $T_{\max }$ and from -4.9 to $-8.3^{\circ} \mathrm{C}$ for $T_{\min }$. The patterns of $T_{\text {max }}$ and $T_{\text {min }}$ simulated by RCM were similar to those simulated by GCM, but the differences with the observed data were smaller and during summer they were not statistically significant (Table 4). Both climate simulations, however, were not able to reproduce the variability of $T_{\max }$ and $T_{\min }$ as demonstrated by the comparison of the percentiles of the cumulated empirical distribution function (Figs. 5 \& 6). In this case RCM outputs were also more precise than the GCM outputs, but failed in reproducing the lower and upper end of the distributions, with errors rather difficult to correct because they were not systematic.

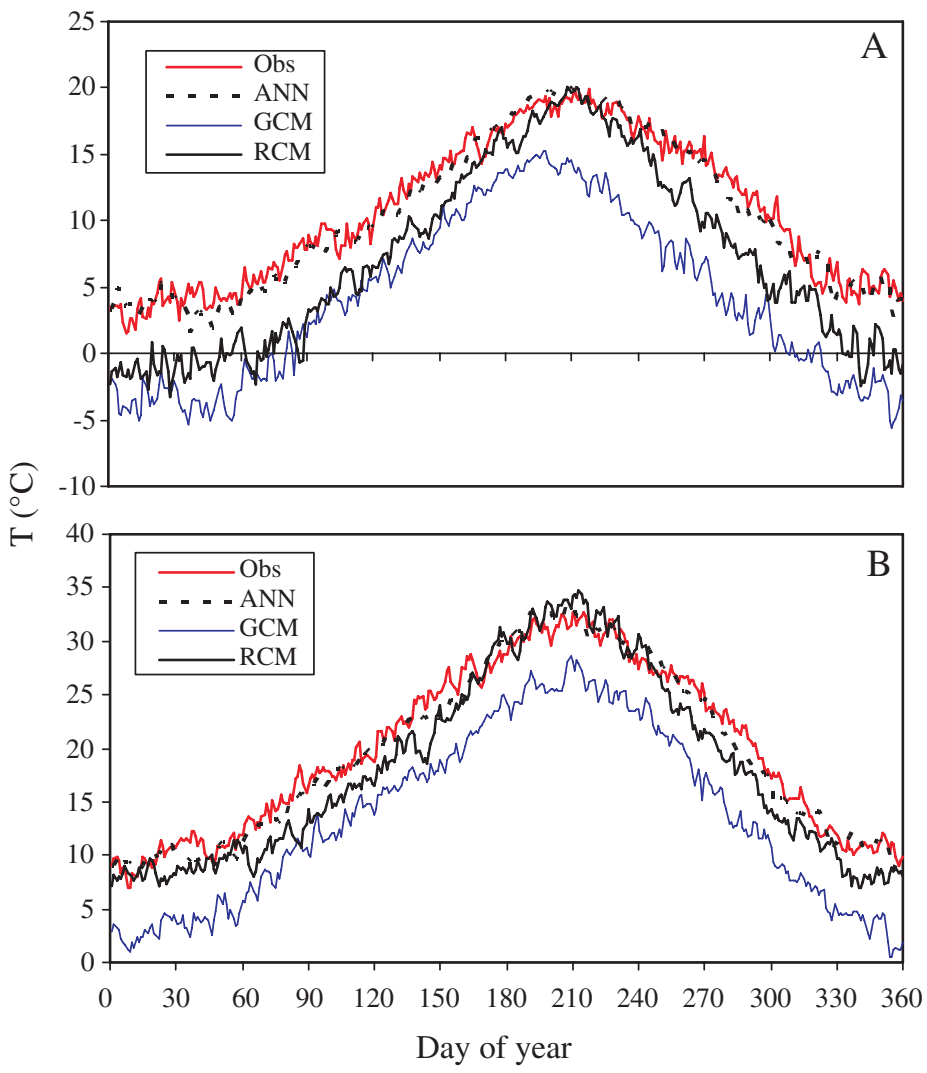

Fig. 4. Mean annual trend of observed (Obs) and simulated (ANN, GCM and RCM) $T_{\min }(\mathrm{A})$ and $T_{\max }$ (B) at the Florence weather station
Table 4. Observed (Obs), GCM, RCM and ANN mean seasonal temperature, $\pm \mathrm{SD} .{ }^{*} \mathrm{p}<0.05$

\begin{tabular}{|llrr|}
\hline Season & Scenario & \multicolumn{1}{c|}{$T_{\max }$} & $T_{\min }$ \\
\hline Winter & Obs 1977-90 & $11.5 \pm 4.2$ & $4.8 \pm 3.9$ \\
& ANN 1977-90 & $11.2 \pm 3.6$ & $4.4 \pm 3.4$ \\
& GCM 1977-90 & $5.3^{*} \pm 4.7$ & $-2.6^{*} \pm 4.6$ \\
& RCM 1977-90 & $9.6^{*} \pm 3.7$ & $-0.4^{*} \pm 4.1$ \\
Spring & Obs 1977-90 & $22.7 \pm 5.3$ & $12.3 \pm 3.7$ \\
& ANN 1977-90 & $22.1 \pm 4.4$ & $11.8 \pm 3.4$ \\
& GCM 1977-90 & $17.1^{*} \pm 4.6$ & $7.4^{*} \pm 4.3$ \\
& RCM 1977-90 & $20.6^{*} \pm 6.2$ & $9.1^{*} \pm 4.8$ \\
Summer & Obs 1977-90 & $29.5 \pm 3.9$ & $17.6 \pm 2.8$ \\
& ANN 1977-90 & $29.8 \pm 3.9$ & $17.9 \pm 2.4$ \\
& GCM 1977-90 & $23.8^{*} \pm 5.8$ & $11.4^{*} \pm 4.3$ \\
& RCM 1977-90 & $29.3 \pm 5.9$ & $16.0^{*} \pm 4.3$ \\
& Obs 1977-90 & $15.3 \pm 5.4$ & $8.4 \pm 5$ \\
& ANN 1977-90 & $14.9 \pm 4.8$ & $7.9 \pm 4.1$ \\
& GCM 1977-90 & $8.1^{*} \pm 5.8$ & $0.1^{*} \pm 5.4$ \\
& RCM 1977-90 & $12.7^{*} \pm 5.4$ & $4.0^{*} \pm 5.5$ \\
\hline
\end{tabular}

On the other hand, the simulated temperatures by the ANN model confirmed the positive agreement between observed and ANN downscaled data found in the testing analysis (Fig. 4). The differences between the seasonal values of downscaled and observed $T_{\max }$ and $T_{\min }$ were not significant (Table 4 ). Also the comparison of the percentiles of the cumulated empirical distribution function using qq plots demonstrated the capability of the ANN model to reproduce the variability of the observed $T_{\max }$ and $T_{\min }$ in contrast with the results reported for GCM and RCM (Figs. 5 \& 6).

Future climate scenarios. The mean seasonal values of $T_{\max }$ and $T_{\min }$ simulated by GCM, RCM and ANN for A2 and B2 future climate scenarios are reported in Table 5. As expected $T_{\max }$ and $T_{\min }$ obtained from GCM, RCM and ANN for the period 2087-2100 were higher than those obtained for the present climate. In particular, the differences in $T_{\text {min }}$ between GCM and ANN for both the scenarios were marked for all the seasons, with maximum differences predicted for winter and autumn (up to $-7.4^{\circ} \mathrm{C}$ ). In contrast, the differences were smaller for $T_{\max }$ (up to $-5.8^{\circ} \mathrm{C}$ ), with very close temperatures during summer $\left(-1^{\circ} \mathrm{C}\right)$. The differences between RCM and ANN were rather small in both future scenarios, especially for $T_{\max }$. However, $T_{\min }$ and $T_{\max }$ simulated by GCM and RCM produced results closer to ANN downscaled data than that under the present climate. This is because GCM and RCM predicted higher increases in $T_{\max }$ and $T_{\min }$ than those predicted by ANN downscaled data. More specifically, for the A2 scenario, ANN data showed an average annual increase in $T_{\max }$ and $T_{\min }$ of 4.3 and $3^{\circ} \mathrm{C}$ respectively, whereas respective $T_{\max }$ and $T_{\min }$ increases for $\mathrm{RCM}$ were 5.5 and $5.3^{\circ} \mathrm{C}$, and for $\mathrm{GCM}$ were 7.2 and 


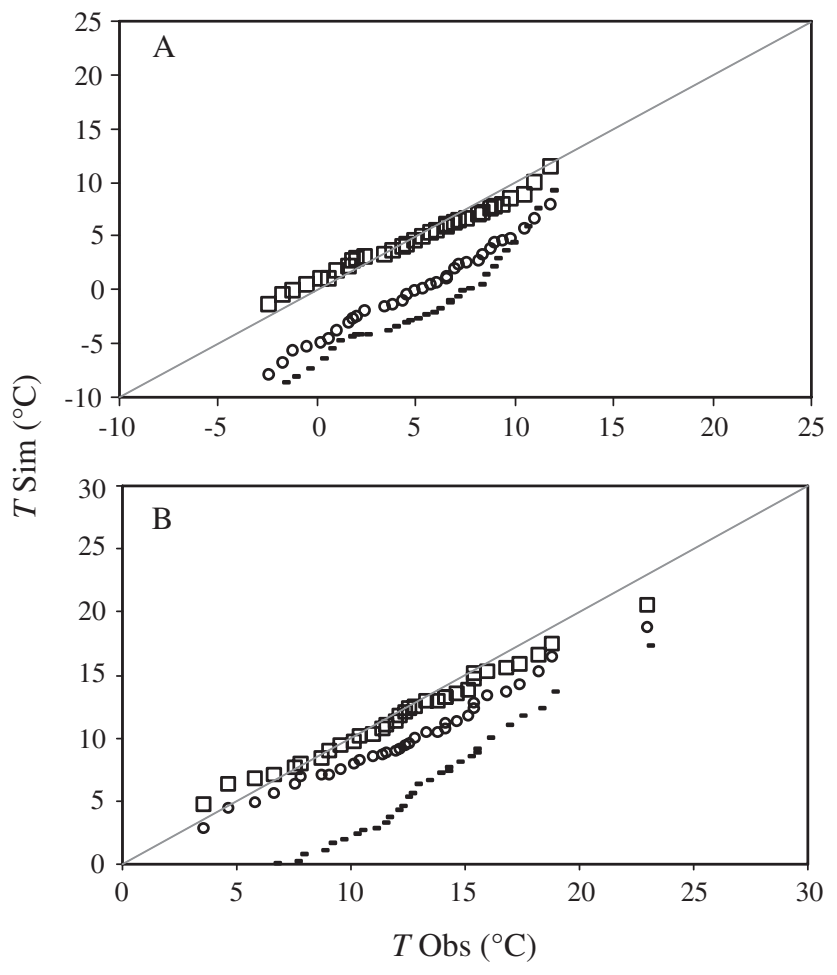

Fig. 5. Quantile-Quantile plots of GCM, RCM and ANN temperatures in winter. (A) $T_{\min }$ (B) $T_{\max }$. (口): ANN, (O): RCM, $(-)$ : GCM

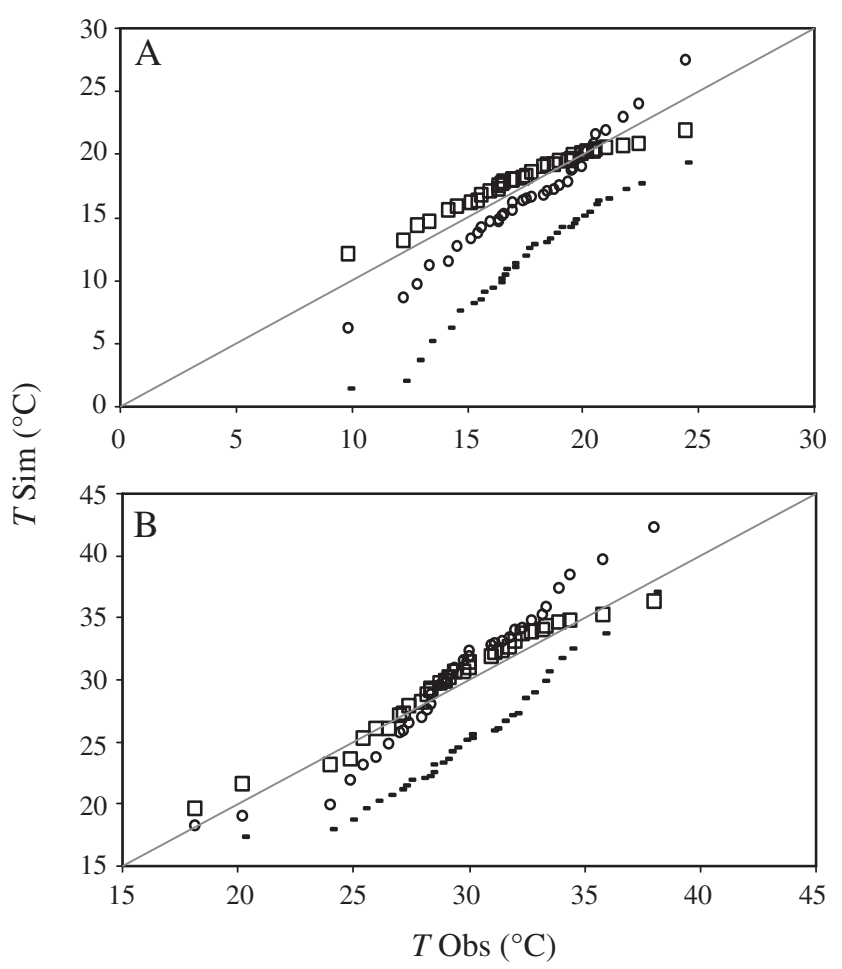

Fig. 6. Quantile-Quantile plots of GCM, RCM and ANN temperature in summer. (A) $T_{\min }$ (B) $T_{\max }$ ( $(\square)$ : ANN, (O): RCM,

$$
\text { (-): GCM }
$$

Table 5. Seasonal mean and SD of $T_{\max }$ and $T_{\min }$ calculated using ANN, GCM and RCM data for A2 and B2 scenarios (2087-2100), and temperature increases with respect to 'present period' (1977-1990) of each model

\begin{tabular}{|c|c|c|c|c|c|}
\hline \multirow{3}{*}{$\begin{array}{l}\text { Season } \\
\text { Winter }\end{array}$} & \multirow{3}{*}{$\begin{array}{l}\text { Scenario } \\
\text { ANN A2 }\end{array}$} & \multicolumn{2}{|c|}{$T_{\max }$} & \multicolumn{2}{|l|}{$T_{\min }$} \\
\hline & & \multicolumn{2}{|c|}{ Mean Increase } & \multicolumn{2}{|c|}{ Mean Increase } \\
\hline & & $13.8 \pm 3.5$ & +2.6 & $7.2 \pm 3.4$ & +2.9 \\
\hline & GCM A2 & $9.8 \pm 4.9$ & +4.5 & $1.0 \pm 4.5$ & +3.6 \\
\hline & RCM A2 & $12.8 \pm 3.5$ & +3.2 & $3.6 \pm 4.2$ & +3.9 \\
\hline & ANN B2 & $13.1 \pm 3.6$ & +1.9 & $6.8 \pm 3.5$ & +2.5 \\
\hline & GCM B2 & $8.1 \pm 5.1$ & +2.8 & $-0.3 \pm 4.7$ & +2.3 \\
\hline & RCM B2 & $12.2 \pm 3.5$ & +2.7 & $3.0 \pm 4.1$ & +3.4 \\
\hline \multirow[t]{6}{*}{ Spring } & ANN A2 & $27.6 \pm 5.7$ & +5.6 & $15.4 \pm 3.7$ & +3.6 \\
\hline & GCM A2 & $24.2 \pm 7.2$ & +7.2 & $11.9 \pm 5.1$ & +4.5 \\
\hline & RCM A2 & $26.7 \pm 7.3$ & +6.2 & $14.2 \pm 5.8$ & +5.1 \\
\hline & ANN B2 & $26.1 \pm 5.7$ & +4.1 & $14.4 \pm 3.8$ & +2.6 \\
\hline & GCM B2 & $21.7 \pm 6.4$ & +4.7 & $10.6 \pm 4.9$ & +3.2 \\
\hline & RCM B2 & $25.0 \pm 7.1$ & +4.4 & $12.8 \pm 5.1$ & +3.7 \\
\hline \multirow[t]{6}{*}{ Summer } & ANN A2 & $36.2 \pm 2.9$ & +6.3 & $21.3 \pm 1.4$ & +3.4 \\
\hline & GCM A2 & $36.6 \pm 6.2$ & +12.8 & $18.8 \pm 4.5$ & +7.4 \\
\hline & RCM A2 & $37.2 \pm 5.6$ & +7.9 & $23.2 \pm 4.1$ & +7.2 \\
\hline & ANN B2 & $34.9 \pm 3.2$ & +5.1 & $20.6 \pm 1.6$ & +2.7 \\
\hline & GCM B2 & $33.9 \pm 6.5$ & +10 & $16.5 \pm 4.2$ & +5.1 \\
\hline & RCM B2 & $34.9 \pm 5.9$ & +5.6 & $20.9 \pm 4.6$ & +4.9 \\
\hline \multirow[t]{6}{*}{ Fall } & ANN A2 & $18.1 \pm 6.2$ & +3.3 & $10.2 \pm 4.5$ & +2.4 \\
\hline & GCM A2 & $12.6 \pm 6.9$ & +4.5 & $3.7 \pm 6.1$ & +3.6 \\
\hline & RCM A2 & $17.5 \pm 5.5$ & +4.8 & $9.0 \pm 5.3$ & +5.0 \\
\hline & ANN B2 & $17.2 \pm 6$ & +2.4 & $9.8 \pm 4.4$ & +2.0 \\
\hline & GCM B2 & $11.4 \pm 7.5$ & +3.4 & $2.4 \pm 6.2$ & +2.2 \\
\hline & RCM B2 & $16.5 \pm 5.4$ & +3.8 & $7.6 \pm 5.0$ & +3.5 \\
\hline
\end{tabular}

$4.6^{\circ} \mathrm{C}$. The same trend was observed for the B2 scenarios, even though changes in temperatures were lower (Table 5).

\subsection{Crop impact analyses}

\subsubsection{Present climate}

The observed GCM, RCM and ANN data of $T_{\max }$ and $T_{\min }$ for the period 1977-1990 were used as input climate variables of the CropSyst model to simulate the main crop development stages of sunflower and winter wheat. According to previous results, the ANN downscaled temperature data allowed us to produce the most precise estimates of the dates for the crop developmental stages (Tables $6 \&$ 7). More specifically, the mean errors in predicting the crop developmental stages of both sunflower and wheat using the ANN data were always within $8 \mathrm{~d}$, whereas those calculated using GCM were much wider ranging from 40 to $104 \mathrm{~d}$ in sunflower and from 7 to $36 \mathrm{~d}$ in winter wheat. The use of RCM data substantially improved the simulation of crop development stages and the mean errors ranged from +16 to $+35 \mathrm{~d}$ in sunflower and from 0 to 
$+26 \mathrm{~d}$ in wheat (Tables 5 \& 6). The ability to simulate developmental stages using the GCM and RCM data was, however, different for the 2 crops. For example RCM performed adequate simulations for winter wheat (no significant differences were detected at grain filling and maturation stages), whereas for sunflower all the dates of the development stages were significantly different from those obtained using the observed climate data. This may be related to the ability of GCM and RCM to better reproduce the observed patterns of $T_{\max }$ and $T_{\min }$ during the winter and spring seasons than in summer and fall seasons (Table 4), and to better reproduce the temperature responses of the 2 crops. For sunflower, the lower temperatures simulated by RCM resulted in a slower development of the crop and then a delay in the main development stages. In winter wheat, the lower temperatures simulated by
RCM and GCM had a lesser effect on the rate of the crop development, because the lower availability of daily thermal units during the development phase between emergence and anthesis was compensated by a higher availability of daily chill unit, i.e. vernalisation requirement (see 'CropSyst model' in 'Materials and methods'). Thus, in GCM and RCM, vernalization requirement was reached faster than using observed and ANN data, allowing a higher rate of thermal unit accumulation. This explains the earlier emergence and anthesis exhibited when using RCM and GCM data in comparison to that exhibited when using observed and ANN data.

The effects of using different temperature datasets (GCM, RCM and ANN) on the simulation of crop developmental stages were investigated not only in terms of mean differences in the development stage

Table 6. Helianthus annuus. Day of year (DOY; mean $\pm \mathrm{SD}$ ) of simulated sunflower development stages computed using observed (Obs), GCM, RCM and ANN temperature data for 'present period' (1977-1990) and future climate scenarios (A2, B2) for the period $2087-2100 .{ }^{*} \mathrm{p} \leq 0.05$

\begin{tabular}{|lccccc}
\hline & Sowing & Emergence & Anthesis & Grain filling & Maturation \\
\hline Present period (1977-1990) & & & & & \\
Obs & $87.5 \pm 7.5$ & $103.4 \pm 9.6$ & $188.3 \pm 7.2$ & $192.1 \pm 7.4$ & $245.5 \pm 11.7$ \\
ANN & $93.6 \pm 11.4$ & $111.1 \pm 10.2$ & $192.4 \pm 3.2$ & $195.8 \pm 3.2$ & $247.6 \pm 6.2$ \\
GCM & $128.1 \pm 7.7$ & $147.2^{*} \pm 8.5$ & $245.7^{*} \pm 18$ & $259.1^{*} \pm 23.9$ & $349.2^{*} \pm 13.2$ \\
RCM & $113.4 \pm 12.7$ & $129.3^{*} \pm 12.9$ & $204.3^{*} \pm 11.5$ & $208.1^{*} \pm 12$ & $280.2^{*} \pm 37.6$ \\
A2 scenario (2087-2100) & & & & & \\
ANN & $82.4 \pm 5.2$ & $96.6 \pm 5.4$ & $168.6 \pm 2.6$ & $171.6 \pm 2.7$ & $211.4 \pm 2.6$ \\
GCM & $101.2 \pm 9.7$ & $115.9 \pm 9.3$ & $184.3 \pm 5.4$ & $187.1 \pm 5.6$ & $22.6 \pm 6.5$ \\
RCM & $89.1 \pm 7.7$ & $104.3 \pm 7.2$ & $172.7 \pm 5.3$ & $175.5 \pm 5.5$ & $207.6 \pm 4.6$ \\
B2 scenario (2087-2100) & & & & & \\
ANN & $83.4 \pm 4.9$ & $98.9 \pm 5.5$ & $173.8 \pm 2.4$ & $176.9 \pm 2.3$ & $218.8 \pm 3.1$ \\
GCM & $106.6 \pm 12.6$ & $122.4 \pm 12.8$ & $195.3 \pm 7$ & $198.3 \pm 7.4$ & $243.6 \pm 12.8$ \\
RCM & $93.1 \pm 9.8$ & $107.4 \pm 9.9$ & $180.1 \pm 7.5$ & $183.4 \pm 7.3$ & $219.6 \pm 10.5$ \\
\hline
\end{tabular}

Table 7. Triticum aestivum. Day of year (DOY; mean \pm SD) of simulated winter wheat development stages computed using observed (Obs), GCM, RCM and ANN temperature data for 'present period' (1977-1990) and future climate scenarios (A2, B2) for the period 2087-2100. ${ }^{*} \mathrm{p} \leq 0.05$

\begin{tabular}{|lccrrr|}
\hline & Sowing & Emergence & Anthesis & Grain filling & Maturation \\
\hline Present period (1977-1990) & & & & & \\
Obs & $323.2 \pm 13.2$ & $340 \pm 13.8$ & $135.1 \pm 5.9$ & $158.5 \pm 5.9$ & $183.2 \pm 7.1$ \\
ANN & $318.5 \pm 11.7$ & $334.8 \pm 10.7$ & $135.1 \pm 5.7$ & $162.6 \pm 5.4$ & $183.5 \pm 4.8$ \\
GCM & $3005^{*} \pm 1.2$ & $314.6^{*} \pm 2.2$ & $98.2^{*} \pm 2.4$ & $147.2^{*} \pm 8.1$ & $190.2^{*} \pm 5.1$ \\
RCM & $3091^{*} \pm 9.4$ & $324.6^{*} \pm 8.9$ & $108.8^{*} \pm 7.4$ & $156.7 \pm 8.7$ & $182.8 \pm 9.5$ \\
A2 scenario (2087-2100) & & & & \\
ANN & $338.5 \pm 17.4$ & $355.8 \pm 15.1$ & $130.8 \pm 3.7$ & $148.4 \pm 2.9$ & $164.7 \pm 3.8$ \\
GCM & $306.3 \pm 9.1$ & $321.1 \pm 9$ & $116.1 \pm 8.9$ & $147.5 \pm 4.1$ & $170.6 \pm 5.1$ \\
RCM & $333.2 \pm 11.7$ & $349.9 \pm 10.9$ & $129.1 \pm 5.5$ & $148.6 \pm 5.3$ & $164.2 \pm 5.6$ \\
B2 scenario (2087-2100) & & & & \\
ANN & $336.4 \pm 21$ & $353.4 \pm 19.4$ & $132.8 \pm 4.9$ & $152.8 \pm 3.8$ & $168.8 \pm 3.6$ \\
GCM & $303.6 \pm 4.4$ & $320.5 \pm 5.6$ & $115.5 \pm 9.8$ & $153.3 \pm 7$ & $177.5 \pm 8$ \\
RCM & $331.2 \pm 16.8$ & $347.5 \pm 16.1$ & $127.8 \pm 8.6$ & $151.8 \pm 8.4$ & $170.7 \pm 7.6$ \\
\hline
\end{tabular}


Table 8. Helianthus annuus. Extreme temperature events $\left(\mathrm{EE}>T_{\max }\right.$ and $\mathrm{EE}<T_{\min }$ respectively) at the sensitive development stages $( \pm 3 \mathrm{~d})$ of the sunflower, computed using observed (Obs), GCM, RCM and ANN climatic data for 'present period' (1977-1990) and future climate scenarios (A2, B2) for the period 2087-2100. Data are total number of days with extreme events / total number of days (\%)

\begin{tabular}{|c|c|c|c|c|c|}
\hline & $\begin{array}{r}\text { EE } \\
\text { Anthesis }\end{array}$ & $\begin{array}{l}>T_{\max } \\
\text { Grain filling }\end{array}$ & Sowing & $\begin{array}{c}\mathrm{EE}<T_{\min } \\
\text { Emergence }\end{array}$ & Anthesis \\
\hline \multicolumn{6}{|c|}{ Present period (1977-1990) } \\
\hline Obs & 0.0 & 1.02 & 18.4 & 12.2 & 6.12 \\
\hline ANN & 4.08 & 1.02 & 10.2 & 2.04 & 0.0 \\
\hline GCM & 1.02 & 1.02 & 26.5 & 6.12 & 86.7 \\
\hline $\mathrm{RCM}$ & 25.5 & 25.5 & 34.7 & 18.4 & 10.2 \\
\hline \multicolumn{6}{|c|}{ A2 scenario (2087-2100) } \\
\hline ANN & 12.2 & 24.5 & 1.02 & 2.04 & 0.0 \\
\hline GCM & 51.0 & 59.2 & 38.8 & 9.18 & 6.12 \\
\hline $\mathrm{RCM}$ & 61.2 & 57.1 & 26.5 & 5.1 & 0.0 \\
\hline \multicolumn{6}{|c|}{ B2 scenario $(2087-2100)$} \\
\hline ANN & 10.2 & 9.18 & 11.2 & 1.02 & 0.0 \\
\hline GCM & 62.2 & 68.4 & 39.8 & 18.4 & 8.16 \\
\hline $\mathrm{RCM}$ & 34.7 & 26.5 & 30.6 & 24.5 & 4.08 \\
\hline
\end{tabular}

following developmental phases (i.e. emergence, anthesis, grain filling and physiological maturity), since their developmental rates were driven only by the accumulation of degree days. In contrast, for wheat the higher temperatures caused a delay of wheat sowing time, since the cool temperature required for sowing, i.e. $7^{\circ} \mathrm{C}$ or lower mean temperature for $5 \mathrm{~d}$, was attained later (15 d). Moreover, the increase in winter temperatures always had a lower effect on the developmental rate up to anthesis, since the time to complete the vernalization requirement was longer. Thus, only the developmental stages after anthesis (i.e. grain filling and maturity stages) were accelerated by higher temperature.

On the basis of these crop behaviours, the use of temperature data obtained from different climate datasets (GCM, RCM and ANN) directly affected the impact of climate change on the dates of the main crop devel-

dates, but also in terms of ability to accurately represent incidences of extreme climatic events during crop development. According to the selected threshold for $T_{\max }$ and $T_{\min }$ extreme events reported in Table 2, ANN downscaled temperature data allowed the most precise reproduction of the frequency of these extreme events in all the selected development stages for both crops (Tables 8 \& 9). Only in 1 case was the observed data $>10 \%$ higher than the simulated data (EE $>T_{\max }$ at grain filling for wheat). In contrast, GCM and RCM datasets poorly reproduced the frequency of climate extremes. For sunflower, GCM highly overestimated the number of $\mathrm{EE}<T_{\min }$ at maturation (81\%), while RCM overestimated the number of EE > $T_{\max }$ at anthesis and grain filling, and EE < $T_{\text {min }}$ at sowing (Table 8). For wheat, GCM largely overestimated the number of EE < $T_{\min }$ in all phenological stages. The same patterns were observed for RCM data, even if the differences were smaller (Table 9).

\subsubsection{Future climate scenarios}

The general increase in temperature predicted by GCM, RCM and ANN models had different effects on sunflower and wheat development. In particular, sowing time of sunflower was advanced, since the minimal phenological threshold, i.e $13^{\circ} \mathrm{C}$ or higher mean temperature for $5 \mathrm{~d}$, was reached earlier $(20 \mathrm{~d})$. The same was applicable for the
Table 9. Triticum aestivum. Extreme temperature events (EE $>T_{\max }$ and $\mathrm{EE}<T_{\min }$ respectively) at the sensitive development stages $( \pm 3 \mathrm{~d})$ of the winter wheat, computed using observed (Obs), GCM, RCM and ANN climatic data for 'present period' (1977-1990) and future climate scenarios (A2, B2) for the period 2087-2100. Data are total number of days with extreme events / total number of days (\%)

\begin{tabular}{|c|c|c|c|c|c|}
\hline & $\begin{array}{r}\text { El } \\
\text { Anthesis }\end{array}$ & $\begin{array}{l}T_{\max } \\
\text { arain filling }\end{array}$ & Sowing & $\begin{array}{c}\mathrm{EE}<T_{\min } \\
\text { Emergence }\end{array}$ & Anthesis \\
\hline \multicolumn{6}{|c|}{ Present period (1977-90) } \\
\hline Obs & 7.7 & 17.6 & 13.2 & 15.9 & 15.4 \\
\hline ANN & 0.0 & 3.3 & 4.4 & 19.8 & 6.6 \\
\hline GCM & 0.0 & 0.0 & 58.2 & 70.3 & 97.8 \\
\hline $\mathrm{RCM}$ & 0.0 & 2.2 & 16 & 40.7 & 96.7 \\
\hline \multicolumn{6}{|c|}{ A2 scenario $(2087-2100)$} \\
\hline ANN & 40.7 & 30.8 & 6.6 & 12.1 & 0.0 \\
\hline GCM & 8.8 & 14.3 & 42.9 & 58.2 & 48.4 \\
\hline $\mathrm{RCM}$ & 30.8 & 42.9 & 20.9 & 48.4 & 13.2 \\
\hline \multicolumn{6}{|c|}{ B2 scenario (2087-2100) } \\
\hline ANN & 27.5 & 28.6 & 1.1 & 41.8 & 1.0 \\
\hline GCM & 0.0 & 3.3 & 37.4 & 56 & 64.8 \\
\hline $\mathrm{RCM}$ & 27.5 & 28.6 & 17.6 & 39.6 & 25.3 \\
\hline
\end{tabular}


also rather similar, whereas those obtained using the GCM data were still quite different (Tables 8 \& 9). However, even if the differences obtained from GCM, RCM and ANN climate date sets between the dates of the main developmental stages and between incidences of extreme climate events in these stages were smaller in future scenarios than for the present climate, the analysis of the relative changes (i.e. differences between future and present CropSyst model outputs) showed that the use of GCM and RCM data resulted in climate change impacts that were different from those obtained using ANN data. For example, the mean reductions in the duration of the growing seasons in sunflower were as follows: $25 \mathrm{~d}$ using ANN, $100 \mathrm{~d}$ using GCM and $48 \mathrm{~d}$ using RCM. The changes in the frequency of extreme events in relation to developmental stages in wheat were substantially different $(+12 \%$ in $\mathrm{ANN},-12 \%$ in $\mathrm{GCM}$ and $-2 \%$ in $\mathrm{RCM})$.

\section{CONCLUSIONS}

With expected increases in climatic variability and extreme events, there is a need to assess future impacts, in particular on the year to year variability of crop yield. One problem in relation to these needs is the coarse resolution of the available tools (i.e. GCM). The tools used to reproduce future climate conditions failed to simulate climate variability in local and regional weather. To fill this gap, 2 conceptually distinct approaches have been developed: nested modelling (such as RCM) and empirical downscaling that uses large-scale predictions from GCMs to develop regional climate change scenarios.

Given that this study was carried out using the climate data of 1 weather station only, wider testing may be required for greater confidence in the findings. The present study confirmed that, even if dynamic downscaling (i.e. RCM data) allowed us to increase the spatial resolution of GCMs, the RCM datasets had problems in reproducing temperature patterns in an area characterised by a complex morphology. The difference between the actual altitude of the weather station (Ximeniano, Florence) and the grid point altitude $(-422.2 \mathrm{~m})$ played an important role in the underestimation of $T_{\max }$ and $T_{\min }$ by RCM. In contrast, a statistical downscaling approach with GCM large-scale variables as predictors (e.g. ANN model) allowed a good simulation of temperature patterns $\left(T_{\max }\right.$ and $\left.T_{\min }\right)$. Following these results, the crop phenological stages and the related climate extreme events were also better reproduced using ANN climate data.

Moreover, the use of HadCM3 and HadRM3P climate data in climate change impact assessments resulted in higher changes in the length of develop- ment phases and in the frequency of extreme climate events during the most sensitive development stages compared with those obtained using ANN climate data.

However, both the downscaling procedures proved to have certain limitations for use in climate change impact assessments. The dynamic downscaling approach (i.e. RCM) has to be used by applying the change between present day and future simulated climate to the observed baseline climate (i.e. 'delta change technique'), because of its low capacity to effectively reproduce present climate conditions. The statistical downscaling approach (i.e. ANN) has to be used when applying relationships developed from the present day climate to future climate scenarios. Unfortunately, the 'delta change technique' cannot be used for evaluating the impact of climate change on climate extremes (such as in this study), as the future variability of climate parameters is expected to be the same as that of the present climate. The relationship developed from the present day climate in the statistical downscaling approach cannot be verified under different climate forcing conditions.

Acknowledgements. We thank C. Goodess for critically reviewing the paper and A. Wittacker for English language proofreading. This research has been supported by the Commission of the EU (Project MICE n. EVK2-CT-2001-00118).

\section{LITERATURE CITED}

Adams RM, McCarl BA, Mearns LO (2003) The economic effects of spatial scale of climate scenarios: an example from US agriculture. Clim Change 60:131-148

Bárdossy A (1997) Downscaling from GCMs to local climate through stochastic linkages. J Environ Manag 49:7-17

Bindi M, Maselli F (2001) Extension of crop model outputs over the land surface by the application of statistical and neural network techniques to topographical and satellite data. Clim Res 16:237-246

Cannon AJ, Whitfield PH (2002) Downscaling recent streamflow conditions in British Columbia, Canada using ensemble neural network models. J Hydrol 259:136-151

Carbone G, Kiechle W, Locke L, Mearns LO, McDaniel L, Downton M (2003) Response of soybeans and sorghum to climate change scenarios in the southeastern United States. Clim Change 60:73-98

Cavazos T (2000) Using self-organizing maps to investigate extreme climate events: an application to wintertime precipitation in the Balkans. J Clim 13:1718-1732

Chen D, Chen Y (2003) Association between winter temperature in China and upper air circulation over East Asia revealed by canonical correlation analysis. Global Planet Change 37:315-325

Crane RG, Hewitson BC (1998) Doubled $\mathrm{CO}_{2}$ climate change scenarios for the Susquehanna Basin: precipitation. Int J Climatol 18:65-76

Doherty RM, Mearns LO, Reddy KR, Downton M, McDaniel L (2003) The effect of spatial scale of climate scenarios on 
simulation of cotton yields in the Southeast US. Clim Change 60:99-130

Easterling W, Mearns LO, Hays C (2001) Comparison of agricultural impacts of climate change calculated from high and low resolution climate model scenarios. Part II: The effect of adaptations. Clim Change 51:173-197

Gardner MW, Dorling SR (1998) Artificial neural networks (the multilayer perceptron) - a review of applications in the atmospheric sciences. Atmos Environ 32:2627-2636

Gordon C, Cooper C, Senior CA, Banks H, Gregory JM, Johns TC, Mitchell JFB, Wood RA (2000) Simulation of SST, sea ice extents and ocean heat transports in a version of the Hadley Centre coupled model without flux adjustments. Clim Dyn 16:147-168

Harrison PA, Butterfield RE (1996) Effect of climate change on Europe-wide winter wheat and sunflower productivity. Clim Res 7:225-241

Haskett JD, Pachepsky YA, Acock B (2000) Effect of climate and atmospheric change on soybean water stress: a study of Iowa. Ecol Model 135:265-277

Hornik K, Stinchcombe M, White H (1989) Multilayer feedforward networks are universal approximators. Neural Netw 2:359-366

Hulme M, Jenkins GJ, Lu X, Turnpenny JR and 8 others (2002) Climate change scenarios for the United Kindom: the UKCIP02 Scientific Report. Tyndall Centre for Climate Change Research, University of East Anglia, Norwich

Huth R (2001) Disaggregating climatic trends by classification of circulation patterns. Int J Climatol 21:135-153

Huth R (2002) Statistical downscaling of daily temperature in central Europe. J Clim 15:1731-1742

IPCC (2000) Special report on emissions scenarios. Cambridge University Press, Cambridge

Izaurralde RC, Rosenberg NJ, Brown RA, Thomson AM (2003) Integrated assessment of Hadley Center (HadCM2) climate-change impacts on agricultural productivity and irrigation water supply in the conterminous United States. Part II. Regional agricultural production in 2030 and 2095. Agric For Meteorol 117:97-122

Kumar PV, Bindi M, Crisci A, Maracchi G (2005) Detection of variations in air temperature at different time scales during the period 1889-1998 at Firenze, Italy. Clim Change 72:123-150

McClelland JL, Rumelhart DE, PDP Research Group (1986) Parallel distribution processing: exploration in the microstructure of cognition. Vol I: Foundations. MIT Press, Cambridge, MA

McGinnis DL (1994) Predicting snowfall from synoptic simulation: a comparison of linear regression and neural network. In: Hewitson B, Crane R (eds) Neural nets: application in geography. Kluwer, Dordrecht, p 79-99

Mearns LO, Rosenzweig C, Goldberg R (1996) The effect of changes in daily and interannual climatic variability on CERES-wheat: a sensitivity study. Clim Change 32:257-292

Mearns LO, Easterling W, Hays C, Marx D (2001) Comparison of agricultural impacts of climate change calculated from high and low resolution climate change model scenarios. Part I: the uncertainty due to spatial scale. Clim Change 51(2):1-42

Mearns LO, Carbone G, Doherty RM, Tsvetsinskaya E, McCarl BA, Adams RM, McDaniel L (2003) The uncertainty due to spatial scale of climate scenarios in integrated assessments: an example from U.S. agriculture. Integr Assessment 4:225-235

Editorial responsibility: Gregory V. Jones,

Ashland, Oregon, USA
Michaelsen J (1987) Cross-validation in statistical climate forecast models. J Clim Appl Meteorol 26:1589-1600

Narciso G, Ragni P, Venturi A (1992) Agrometeorological aspects of crops in Italy, Spain and Greece. Joint Research Centre, Commission of the European Communities, Brussels-Luxembourg

Olsson J, Uvo CB, Jinno K (2001) Statistical atmospheric downscaling of short-term extreme rainfall by neural networks. Phys Chem Earth 26:695-700

Osborne CP, Chuine I, Viner D, Woodward FI (2000) Olive phenology as a sensitive indicator of future climatic warming in the Mediterranean. Plant Cell Environ 23:701-710

Pope VD, Gallani ML, Rowntree PR, Stratton RA (2000) The impact of new physical parameterizations in the Hadley Centre climate model: HadAM3. Clim Dyn 16:123-146

Porter JR, Gawith M (1999) Temperatures and the growth and development of wheat: a review. Eur J Agron 10:23-36

Régnière J, Bolstad P (1994) Statistical simulation of daily air temperature patterns in eastern North America to forecast seasonal events in insect pest management. Environ Entomol 23:1369-1380

Rosenberg NJ, Brown RA, Izaurralde RC, Thomson AM (2003) Integrated assessment of Hadley Centre (HadCM2) climate change projections on agricultural productivity and irrigation water supply in the conterminous United States. I: climate change scenarios and impacts on irrigation water supply simulated with the HUMUS model. Agric For Metereol 117:73-96

Rumelhart DE, Hinton GE, Williams RJ (1986) Learning internal representations by error propagation. In: Rumelhart DE, McClelland JL (eds) Parallel distributed processing: explorations in the microstructure of cognition, Vol 1. MIT Press, Cambridge, MA

Sailor DJ, Hu T, Li X, Rosen JN (2000) A neural network approach to local downscaling of GCM output for assessing wind power implications of climate change. Renew Energy 19:359-378

Sánchez E, Gallardo C, Gaertner MA, Arribas A, Castro M (2004) Future climate extreme events in the Mediterranean simulated by a regional climate model: a first approach. Global Planet Change 44:163-80

Stockle CO, Donatelli M, Nelson R (2003) CropSyst, a cropping systems simulation model. Eur J Agron 18:289-307

Trigo RM, Palutikof JP (1999) Simulation of daily temperatures for climate change scenarios over Portugal: a neural network model approach. Clim Res 13:45-59

Tsvetsinskaya EA, Mearns LO, Mavromatis T, Gao W, McDaniel LR, Downton MW (2003) The effect of spatial scale of climate change scenarios on simulated maize, winter wheat, and rice production in the southeastern United States. Clim Change 60:37-72

Weichert A, Bürger G (1998) Linear versus nonlinear techniques in downscaling. Clim Res 10:83-93

Widmann M, Schär C (1997) A principal component and longterm trend analysis of daily precipitation in Switzerland. Int J Climatol 17:1333-1356

Wilby RL, Wigley TML, Conway D, Jones PD, Hewitson BC, Main J, Wilks DS (1998) Statistical downscaling of general circulation model output: a comparison of methods. Water Res 34:2995-3008

Wilby RL, Hay LE, Leavesley GH (1999) A comparison of downscaled and raw GCM output: implications for climate change scenarios in the San Juan River basin, Colorado. J Hydrol 225:67-91

Submitted: March 29, 2005; Accepted: December 6, 2005 Proofs received from author(s): February 9, 2006 